\title{
Novel in-situ synthesis of cellulose AGNPS characterization and antibacterial properties
}

\begin{abstract}
The present study reported a simple and a fast method for in-situ antibacterial Ag NPs loading on cellulosic white plain weave (bandage) through chemical reduction technique using sodium borohydride $\left(\mathrm{NaBH}_{4}\right)$. The effect of adding a stabilizing agent, such as polyvinyl pyrrolidone (PVP), was evaluated. The prepared cellulosic samples were characterized by Fourier Transform Infrared spectroscopy (FTIR) and DSC analysis. The treated supports dis-played obvious antibacterial properties for both gram-negative and gram-positive bacteria. The obtained results revealed that the addition of the protective colloid (PVP) generated better antibacterial activity than the fabric treated without PVP.
\end{abstract}

Keywords: cotton, antibacterial activity, silver nano particles, stabilizing agent
Volume 4 Issue I - 2018

\author{
Amel El Ghali,Aroussi Chaabane, Mohamed \\ Hassan V Baouab \\ Faculty of Sciences, Laboratory of Microelectronics and \\ Instrumentation, University of Monastir, Tunisia
}

Correspondence: Amel El Ghali, Faculty of Sciences,

Laboratory of Microelectronics and Instrumentation, University of Monastir, Monastir, Boulevard of Environment, 5019 Monastir, Tunisia, Tel 2165542 0984, Email amelelghali@yahoo.fr

Received: December 30, 2017 | Published: January 12, 2018
Abbreviations: PVP, polyvinyl pyrrolidone; FTIR, fourier transform infrared spectroscopy; $\mathrm{NaBH}_{4}$, sodium borohydride; $\mathrm{AgNO}_{3}$, silver nitrate; DSC, differential scanning calorimetry

\section{Introduction}

Many bacteria are harmless and even highly helpful but a lot of them can cause hundreds of illnesses. ${ }^{1}$ Therefore, there exists a need to develop antibacterial supports which exhibit satisfactory antibacterial properties allowing the protection of the human body. Cellulose is one of the most abundant biopolymers in the nature. It is a renewable material which exhibited hygroscopicity, non-toxicity, biocompatibility, biodegradability and chemical reactivity. It is a carbohydrate polymer composed of repeating D-glucopyranose units and consists of three hydroxyl groups per a hydroglucose unit conferring the cellulose molecule a high degree of functionality. The materials based on cellulose and its derivatives have been employed in a large variety of applications such as textile, food, paper production, biomaterials and pharmaceuticals. ${ }^{2-4}$ Functionalization of cellulose with nanoparticles has attracted great attentions of researchers in recent years. A number of studies have been investigated to improve functions of this material such as antibacterial treatment. ${ }^{5}$ Among different metals, silver is by far the most widely used antibacterial agent because of its efficiency and its strong toxicity against many forms of both gram-positive and gram-negative bacteria. ${ }^{6}$ The structural differences between the two types of bacteria lie in the organization of a key constituent of the membrane, peptidoglycan. Gram negative bacteria display only a thin peptidoglycan layer $(\approx 2-$ $3 \mathrm{~nm}$ ) between the cytoplasmic membrane and the outer membrane. However; Gram-positive bacteria lack the outer membrane but have a peptidoglycan layer of about $30 \mathrm{~nm}$ thick.

The Ag metal has the capacity to attach to bacterial cell membranes, to enter and attack the respiratory chain of the cell, hence inducing the death of the bacteria. ${ }^{7} \mathrm{Ag}$ NPs have been added to a variety of polymeric fibers and have shown successful antibacterial activity. ${ }^{8-11}$ In this investigation, nano silver particles were introduced on the structure of a cellulosic material (a bandage) via a chemical reduction method using sodium borohydride $\left(\mathrm{NaBH}_{4}\right)$ in the presence or not of polyvinyl pyrrolidone (PVP) as stabilizer agent. The in situ direct metallization method was applied in the attempt to obtain a high loading amount and strong bonding force of Ag NPs on the cellulosic surface, thus evading the $\mathrm{Ag}^{+}$contamination problem. The presence of Ag NPs on the surface of the used support was verified by Fourier transform infrared spectroscopy and DSC characterizations. The impact of the adopted treatment on some mechanical properties of the tested fabric was then evaluated. Finally, the survey of the bacterial activity of loaded Ag NPs cellulosic support was evaluated against gram positive and gram negative bacteria.

\section{Experimental}

\section{Materials}

The cellulosic support used in this study is a bandage that was supplied by the central pharmacy of Sousse, Tunisia. The used fabric has the following specification: Plain weave, surface mass $25 \mathrm{~g} / \mathrm{m}^{2}$, thickness $0.3 \mathrm{~mm}$, weft density=warp density $=18$ thread $/ \mathrm{cm}$, weft yarn finesses=warp yarn finesses $=15$ tex. Silver nitrate $\left(\mathrm{AgNO}_{3}\right)$, sodium borohydride $\left(\mathrm{NaBH}_{4}\right)$ and polyvinyl pyrrolidone $(\mathrm{PVP})$ were purchased from Sigma-Aldrich Chemical Company and used as received without further purification.

\section{Preparation of cell/ $\mathrm{Ag}^{\circ}$ material}

In the present work, cellulose fibers were functionalized with Ag nanoparticles by in-situ synthesis. Firstly, the cellulosic support was treated with an aqueous solution of $\mathrm{AgNO}_{3}(0.06$ mol.L-1 $)$ at room temperature for 24hours. Then, it was washed with distilled and deionized water several times until no more silver ions could be identified in the washing water by the chloride test. Subsequently, the $\mathrm{Ag}^{+}$incorporated in cellulose membrane $\left(\mathrm{cell} / \mathrm{Ag}^{+}\right)$were then treated with a reducing agent, namely $\mathrm{NaBH}_{4}$. In order to evaluate the role of PVP, as a protective colloid, we have prepared another solution (the same that the earlier) and we have gradually added an aqueous solution containing $0.2 \% \mathrm{wt} / \mathrm{v}$ of $\mathrm{PVP}$ at $\mathrm{pH} 13-14$. This addition was carried out in an ice ultrasound bath (temperature around $5^{\circ} \mathrm{C}$ ) for 15 minutes. The mixture was then maintained for a further 1 hour at room temperature. At the end of reduction process, the Cell/ $\mathrm{Ag}^{\circ}$ 
became dark brown. The obtained materials were finally dried at $100^{\circ} \mathrm{C}$

\section{Characterization of silver treated fabrics}

FTIR analysis: The chemical changes to cellulosic fabric treated with AgNPs were analyzed on FTIR spectroscopy. Infrared spectra were obtained from $\mathrm{KBr}$ pellets using a Fourier Transform Infrared Spectrometer $\left(\right.$ Nicolet $\left.^{\circledR} 510 \mathrm{M}\right)$ in a transmittance mode in the range of $500-4000 \mathrm{~cm}^{-1}$.

DSC analysis: Heat-flow analysis differential scanning calorimetry (DSC) analysis was conducted using a Setaram instrument by heating the sample from room temperature to $300^{\circ} \mathrm{C}$ at a rate of $10^{\circ} \mathrm{C} \cdot \mathrm{min}^{-1}$.

Mechanical properties: The bandage fabric was tested for the tensile properties ${ }^{12}$ before and after nano Ag treatment. Mechanical properties (breaking load, \% elongation-at-break, Young modulus and rigidity) were determined using LLOYD LR5 Instrument. The tested fabric possess identical warp and weft yarns characteristics. Therefore the mechanical properties were studied only in one direction of the bandage.

Antibacterial activities: Antibacterial activity of untreated and treated samples was tested on the basis of the agar diffusion standard test method. ${ }^{13}$ Four type of bacterial pathogen strains were used: Staphylococus aureus (ATCC 25923) and Vibrio parahaemolyticus (CECT 511) (gram- positive bacteria). Escherchia Coli (ATCC 25922) and Salmonela typhimurium (ATCC 1408) (gram-negative bacteria).

\section{Results and discussion}

\section{FTIR analysis}

The FTIR spectra of untreated and treated supports have been shown in Figure 1. The spectrums of the three supports exhibited the main characteristic adsorption peaks of cellulose. ${ }^{6}$ Indeed, the wide peak at around $3333 \mathrm{~cm}^{-1}$ is assigned to the hydrogen-bonded $\mathrm{OH}$ stretching. The peak at $2890 \mathrm{~cm}^{-1}$ is associated to the $\mathrm{CH}$ stretching and the one at $895 \mathrm{~cm}^{-1}$ belonged to the $\mathrm{CH}_{2}-\mathrm{OH}$ bending groups of cellobiose. The band at $1160 \mathrm{~cm}^{-1}$ is related to C-O-C stretching at the $\beta$ - $(1 \rightarrow 4)$-glycosidic linkage. The peak at $1058 \mathrm{~cm}^{-1}$ corresponded to the $\mathrm{C}-\mathrm{OH}$ (secondary alcohol) stretching vibration.

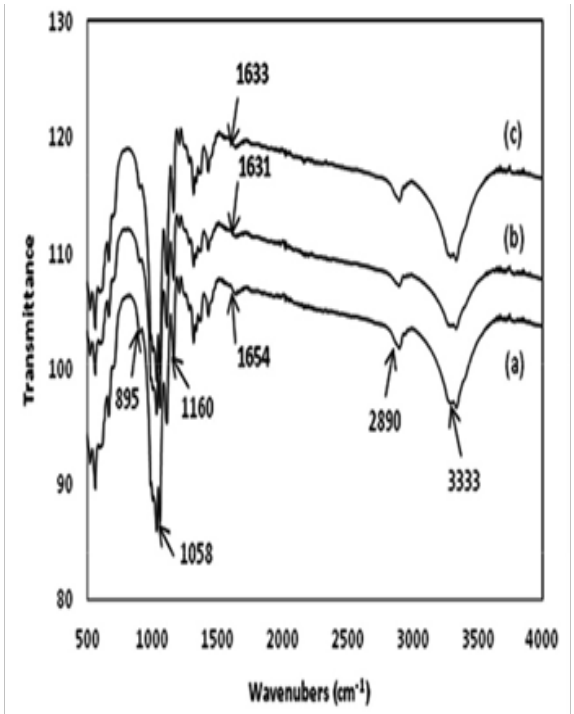

Figure I FTIR spectra of, Untreated support, (b) Cell/Ag prepared with $\mathrm{NaBH} 4$ without PVP and (c) Cell/Ag prepared with $\mathrm{NaBH}_{4}$ using PVP.
The small absorption at around $1654 \mathrm{~cm}^{-1}$ (Figure 1(a)), which confirmed the existence of the double bond $\mathrm{C}=\mathrm{C}$, was shifted to $1631 \mathrm{~cm}^{-1}$ for Cell $/ \mathrm{Ag}$ prepared with $\mathrm{NaBH}_{4}$ without PVP (Figure 1(b)) and to $1633 \mathrm{~cm}^{-1}$ for Cell/Ag prepared with $\mathrm{NaBH}_{4}$ using PVP (Figure 1(c)). Theses peaks are assigned to the vibration of the intercellobiose bonds.

The shift of the peak might be explained by the fact that the nanoparticles of Ag are fixed 77 between the electron pair carried by two local oxygen's (two oxygen's carried by the same 78 carbon). For the rest of the spectra, we noted a perfect juxtaposition between the bands of 79 vibrations in the plan and outside the plan of the different bonds constitutive of the cellulosic 80 structures. The FTIR characterization confirmed that the deposit of Ag NPs is exclusively 81 done at the point of meeting between the two pyranose cycles

\section{Differential scanning calorimetry (DSC) analysis}

The heat treatment DSC curves of the cellulosic material before and after Ag NPs functionalization are given in Figure 2. As can be observed, there is a general stabilization of the cellulose structure that is characterized by:

a. A small shift in the temperature of water loss which passes from $66^{\circ} \mathrm{C}$ for the untreated support to $69^{\circ} \mathrm{C}$ for the treated supports with Ag NPs.

b. A thermal stabilization characterized by a weight loss of the nano Ag treated supports relatively reduced compared to that of untreated one.

c. The temperature of the cellulose decomposition passes from around $235^{\circ} \mathrm{C}$ for the untreated cellulosic material to approximately $270^{\circ} \mathrm{C}$ for the treated ones accompanied by a relatively negligible weight loss compared to that of the untreated sample.

The ratio $(R)$ of the weight loss between the treated sample (DW1) and the untreated one (DW2) is represented as follows:

$$
R=\frac{D W_{2}}{D W_{1}}
$$

Based on the results presented in Figure 2, $R$ is equal to 1.49. This means that the Ag NPs treatment led to a sample's weight loss of 1.49 times than that of the weight loss of the untreated cellulosic sample.

\section{Mechanical properties studies}

The effect of silver nano treatment on breaking load, maximal strain, Young modulus and rigidity has been evaluated in this study. As it can be seen from Table 1, the introduction of silver nano particles into the structure of the fibre causes an improvement in the mechanical properties of the samples. This could be attributed to the small size of nano Ag particles which could penetrate in between the polymer molecules and may be act as filler or cross linking agent which also contribute to the load sharing phenomenon during load application to the material. ${ }^{14}$ In this context, Ag NPs perform as binding components which joins the fibrils with the "bodies" of the fibre, thus strengthening their structure. ${ }^{15}$ Results also revealed that there is a little improvement in the mechanical properties of the Cell/ Ag support prepared with $\mathrm{NaBH}_{4}$ using PVP in comparison the Cell/ Ag support prepared with $\mathrm{NaBH}_{4}$ without PVP. This suggested that the addition of the protective colloid agent allows more insertion of the silver nanoparticles inside the textile structure inducing an increase in the mechanical performances of the tested materials. 


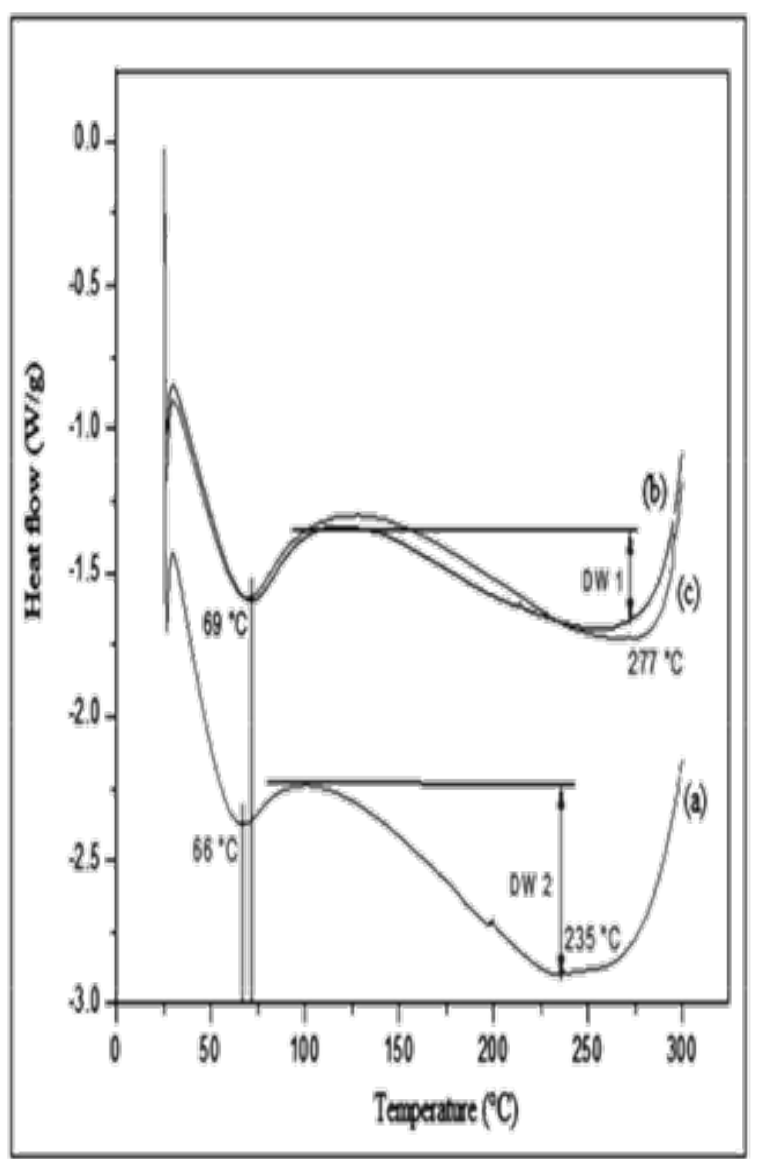

Figure 2 DSC analysis of, (a) Untreated cellulose, (b) Cell/Ag prepared with $\mathrm{NaBH}_{4}$ without PVP and (c) Cell/Ag prepared with $\mathrm{NaBH}_{4}$ using PVP.

\section{Antimicrobial activity studies}

The untreated and treated cellulosic substrates (Cell/Ag prepared with $\mathrm{NaBH}_{4}$ without PVP and Cell/Ag prepared with $\mathrm{NaBH}_{4}$ using PVP) were taken for antimicrobial effect against five well-known bacteria by agar diffusion test. To evaluate the antibacterial activity of the treated cellulosic materials, we have measured the surface of the bandage sample noted by $S_{0}$, and the surface of the inhibition

Table I Mechanical properties of treated and untreated supports zone (if it exists), noted by $S_{\text {fnish }}$. Then, we calculate the ratio $S_{\text {finish }} /$ $S_{0}$. The presence of a clear zone around the sample was recorded as an inhibition against the bacterial strains. As currently envisioned, the reference cellulosic sample, without the Ag addition, has not produce any antimicrobial activities since no inhibition zone was observed. So, the cellulose material was only used as matrix for the dispersion of Ag NPs.

The antibacterial activities results (the ratio $S_{\text {finish }} / S_{0}$ ) of loaded supports with Ag nanoparticles are given in Table 2. As can be seen, the cellulosic supports loaded with Ag NPs exhibited good inhibitory activities against the tested bacterial strains. Indeed, the nano silver particles have an extremely large relative surface area, thus increasing their contact with bacteria or fungi, and vastly improving their bactericidal and fungicidal effectiveness. Nano silver is very reactive with proteins. When contacting bacteria and fungus, it adversely affects cellular metabolism and inhibits cell growth. It also suppresses respiration, the basal metabolism of the electron transfer system, and the transport of the substrate into the microbial cell membrane. Furthermore, it inhibits the multiplication and growth of those bacteria and fungi which cause infection, odor, itchiness and sores.

Results also showed that the Cell/Ag prepared with $\mathrm{NaBH}_{4}$ using PVP displayed higher antimicrobial efficiency than that of Cell/Ag prepared with $\mathrm{NaBH}_{4}$ without PVP, independently of the microbe type. Indeed, this colloid provides overall increase of silver active surface due to high surface to volume ratio of each nanoparticle. In this case, silver nanoparticles were entrapped physically on the cellulose structure and it might be firmer in comparison with the fabric without PVP. In addition to that, when the bandage with $\mathrm{Ag}$ ions are immersed in the reducing agent solution in the presence of PVP (as a protective colloid), the $\mathrm{Ag}$ ions are reduced to $\mathrm{Ag}^{\circ}$ particles, which are stabilized at the ion selective sites of the cellulosic surface without becoming grown or agglomerated. ${ }^{16}$ The obtained results showed the importance of the addition of the stabilizing agent (PVP) in the reduction's reaction of $\mathrm{Ag}^{+}$ions.

As can be shown in Table 1, the E. Coli has lower resistance against antimicrobial activity of Cell/Ag prepared with $\mathrm{NaBH}_{4}$ using PVP in comparison with the other ones. This could be attributed to the thicker cell wall of S. aureus, V. parahaemolyticus and S. typhimurium compared to that of E. Coli. For this, the nano silver particles cannot destroy these bacteria easily.

\begin{tabular}{lllll}
\hline Sample & $\begin{array}{l}\text { Breaking load } \\
(\mathbf{N})\end{array}$ & $\begin{array}{l}\text { Elongation at break } \\
(\%)\end{array}$ & $\begin{array}{l}\text { Young modulus } \\
(\mathbf{M P a})\end{array}$ & $\begin{array}{l}\text { Rigidity } \\
(\mathbf{N} / \mathbf{m})\end{array}$ \\
\hline Untreated support & 40 & 5.6 & 50 & 10521 \\
Cell/Ag prepared with $\mathrm{NaBH}_{4}$ without PVP & 44 & 8.8 & 61.88 & 19425 \\
Cell/Ag prepared with $\mathrm{NaBH}_{4}$ using PVP & 45 & 9.23 & 62 & 21098 \\
\hline
\end{tabular}

Table 2 Antimicrobial activities of treated cellulosic samples

\begin{tabular}{|c|c|c|c|c|}
\hline Sample & E. Coli & S. typhimurium & V. parahaemolyticus & S. aureus \\
\hline Cell/Ag prepared with $\mathrm{NaBH}_{4}$ without PVP & $<\mathrm{I}$ & I & $<1$ & I \\
\hline Cell/Ag prepared with $\mathrm{NaBH}_{4}$ using PVP & 1.05 & 1.15 & 1.17 & 1.16 \\
\hline
\end{tabular}




\section{Conclusion}

In this survey, a cellulosic support (a bandage) has been antimicrobially finished through in situ preparation of silver functionality by applying chemical reduction method using $\mathrm{NaBH}_{4}$ as reducer. The use of a colloid protector, such as PVP, has also been evaluated. Afterwards, the antibacterial activity of the functionalized supports against some bacterial stumps has been tested. This activity was measured by calculating the ration of the inhibition zone surface and bandage sample surface placed in the culture medium. Results showed that the Cell/Ag prepared with $\mathrm{NaBH}_{4}$ using PVP exhibited higher antimicrobial effectiveness than that of Cell/Ag prepared with $\mathrm{NaBH}_{4}$ without PVP. The mechanical properties of the untreated and treated supports has also been examined and it was found that the introduction of AgNPs into the structure of the cellulosic fibres deals with an improvement in terms of breaking load, elongation at break, young modulus and rigidity.

\section{Acknowledgements}

None.

\section{Conflict of interest}

Author declares there is no conflict of interest in publishing the article.

\section{References}

1. Wan C, Li J. Cellulose aerogels functionalized with polypyrrole and silver nanoparticles: In-situ synthesis, characterization and antibacterial activity. Carbohydr Polym. 2016;146:362-367.

2. Coffey DG, Bell DA, Henderson A. Cellulose and cellulose derivatives: Food polysaccharides and their Applications. Marcel Dekker New York, USA; 1995. p. 124.

3. De Souza LMM, Borsali R. Rodlike Cellulose Microcrystals: Structure, Properties, and applications. Macromolecular Rapid Communications. 2004;25(7):771-787.

4. Ververis C, Georghiou K, Christodoulakis N, et al. Fiber dimensions, lignin and cellulose content of various plant materials and their suitability for paper production. Ind Crops Prod. 2004;19(3):245-254.
5. Lin S, Chen L, Huang L, et al. Novel antimicrobial chitosan-cellulose composite films bio conjugated with silver nanoparticles. Ind Crops Prod. 2015;70:395-403.

6. Arain RA, Khatri Z, Memon MH, et al. Antibacterial property and characterization of cotton fabric treated with chitosan $/ \mathrm{AgCl}-\mathrm{TiO}$, colloid. Carbohydr Polym. 2013;96(1):326-331.

7. Morones JR, Elechiguerra JL, Camacho A, et al. The bactericidal effect of silver nanoparticles. Nanotechnology. 2005;16(10):2346-2353.

8. Agelova T, Rangelova N, Uzunova V, et al. Cytotoxicity and antibiofilm activity of $\mathrm{SiO} 2$ /cellulose derivative hybrid materials containing silver nanoparticles. Turk J Chem. 2016;40:1278-1288.

9. Hong KH, Park JL, Sul IH, et al. Preparation of antimicrobial poly(vinyl alcohol) nanofibers containing silver nanoparticles. $J$ Polym Sci B. 2006;44(17):2468-2474.

10. Song J, Birbach NL, Hinestroza JP. Deposition of silver nanoparticles on cellulosic fibers via stabilization of carboxymethyl groups. Cellulose. 2012;19(2):411-424.

11. Yan J, Abdelgawad AM, El-Naggar ME, et al. Antibacterial activity of silver nanoparticles synthesized In-situ by solution spraying onto cellulose. Carbohydr Polym. 2016;147:500-508.

12. ISO 13934-2. Textiles- Tensile properties of fabrics--Part 2: Determination of maximum force using the grab method. International Organization for Standardization. UK; 2014.

13. ISO 20645. Textile fabrics-Determination of antibacterial activity-Agar Diffusion plate test. International Organization for Standardization. UK; 2004.

14. Shaid A, Furgusson M, Wang L. Thermophysiological Comfort Analysis of Aerogel Nanoparticle Incorporated Fabric for Fire Fighter's Protective Clothing. Chemical \& Materials Engineering. 2014;2(2):37-43.

15. Yu H, Xu X, Chen X, et al. Preparation and antibacterial effects of PVA-PVP hydrogels containing silver nanoparticles. J Appl Polym Sci. 2006;103(1):125-133.

16. Velazquez-Velazquez JL, Santos-Flores A, Araujo-Melendez J, et al Anti-biofilm and cytotoxicity of impregnated dressings with silver nanoparticles. Mater Sci Eng C. 2015;49:604-611. 